\title{
La sistematización del clima mediterráneo: identificación, clasificación y caracterización climática de Andalucía (España) ${ }^{1}$
}

\author{
José Gómez-Zotano², Jorge Alcántara-Manzanares³, \\ José Antonio Olmedo-Cobo ${ }^{4}$ y Emilio Martínez-Ibarra ${ }^{5}$
}

\begin{abstract}
RESUMEN
Las clasificaciones zonales -macroclimáticas- son difícilmente aplicables en ámbitos regionales, donde existe una particular interacción de factores climáticos de tipo geográfico y dinámico. Especialmente complejas resultan las heterogéneas regiones sometidas al cambiante clima mediterráneo, que adolecen de una sistematización escalar adecuada. Atendiendo a esta necesidad se presenta, por primera vez, una propuesta de clasificación interescalar basada en estadística multivariante y el criterio experto. El método se aplica a la comunidad autónoma de Andalucía (España), identificándose y caracterizándose cinco regiones climáticas y veintiún tipos climáticos. Se concluye que la metodología utilizada permite su extrapolación a otros ámbitos geográficos complejos, independientemente de la escala espacial y temporal de trabajo.
\end{abstract}

Palabras clave: Clasificación climática, estadística multivariante, Andalucía

\begin{abstract}
Zonal classifications -macroclimatic- are difficult to apply in regional areas where there is a particular interaction of climatic factors of both a geographic and dynamic type. Especially complex are the heterogeneous regions subject to changing Mediterranean climate, which lack proper scalar systematization. In response to this need we present, for the first time, an interscalar classification based on multivariate statistics and expert judgment. The method has been applied to the autonomous community of Andalusia (Spain), where we identified and characterized five climatic regions and twenty one different climatic types. We concluded that this method allows for extrapolation to other geographical areas, regardless of the spatial and temporal scale under investigation.
\end{abstract}

Key words: Climate classification, multivariate statistics, Andalusia

\footnotetext{
1 Los resultados de esta investigación forman parte de los siguientes proyectos: NET323476 subvencionado por la Junta de Andalucía (Centro de Estudios Paisaje y Territorio); ULTRAFORESTS CS02013-47713-P subvencionado por el Ministerio de Economía y Competitividad del Gobierno de España; PID 14-92 subvencionado por la Universidad de Granada. Artículo recibido el 1 de julio de 2014, aceptado el 11 de diciembre de 2014 y corregido el 19 de enero de 2015
}

2 Departamento de Análisis Geográfico Regional y Geografía Física, Universidad de Granada (España). E-mail: jgzotano@ugr.es

3 Departamento de Didáctica de las Ciencias Sociales y Experimentales, Universidad de Córdoba (España). E-mail: b62almaj@uco.es

4 Departamento de Análisis Geográfico Regional y Geografía Física, Universidad de Granada (España). E-mail: jaolmedo@ugr.es

5 Departamento de Análisis Geográfico Regional y Geografía Física, Universidad de Granada (España). E-mail: emibarra@ugr.es 
El clima ejerce una influencia notable en la configuración de los medios naturales de la Tierra y en la antropización que estos han experimentado desde la prehistoria hasta la actualidad, lo que explica el interés que su conocimiento ha suscitado desde la Antigüedad (Viers, 1981: 113; Fernández, 1995: 13). Para la mejor comprensión del sistema climático y su integración en los actuales modelos de planificación territorial, resulta imprescindible la sistematización de un volumen creciente de datos meteorológicos. En este sentido, las clasificaciones climáticas permiten definir y tipificar espacios climáticos con características similares (Khlebnikova, 2009).

Son numerosos los intentos de división del clima en grupos claramente definidos y fácilmente distinguibles (Strahler y Strahler, 2000), si bien es una tarea no exenta de dificultades dada la heterogeneidad climática de cualquier punto del Planeta y la artificialidad inherente a los límites (Blair, 1942). A escala planetaria se han realizado las clasificaciones climáticas de carácter científico más relevantes. Vladimir Köppen presenta en 1900 la primera propuesta de corte cuantitativo (Sparovek et al., 2007: 257); Emmanuel de Martonne en 1909 desarrolla una clasificación climática de tipo geográfico; Charles Thornwaite hacia 1948 elabora una tipificación climática basada principalmente en la evapotranspiración potencial y la precipitación media anual; Juan Papadakis desarrolla entre 1952 y 1975 una zonificación de aplicación agronómica; Arthur Strahler propone en 1974 una clasificación de tipo genético; finalmente, cabe destacar el sistema de clasificación bioclimática a escala planetaria de RivasMartínez, desarrollado entre 1996 y 2009.

Buena parte de los macroclimas definidos en estas clasificaciones zonales son difícilmente reconocibles o de aplicación poco práctica en determinados ámbitos regionales y locales, debido a la particularidad que adquieren en ellos los elementos del clima. El macroclima mediterráneo es un caso paradigmático, ya que presenta una elevada variabilidad derivada de factores geográficos y la gran irregularidad de mecanismos atmosféricos que dirigen su dinámica. Un caso particular, en el contexto geográfico de este macroclima, lo constituye la Península Ibérica (suroeste de Europa), donde la complicada orografía de su territorio provoca que las cla- sificaciones climáticas zonales carezcan de significado (Font, 2000: 239). En consecuencia, en España se han desarrollado otras sistematizaciones del clima como las elaboradas por Allué (1966, 2000), Olcina (1994), RivasMartínez \& Loidi (1999), Capel (2000) o RasiIla (2003). En este territorio, existen ámbitos regionales donde la complejidad climática es todavía mayor, debido a la particular interacción de factores climáticos de tipo geográfico y dinámico, como, por ejemplo, Andalucía.

En esta región son numerosos los estudios climáticos, tanto de tipo analítico como sinóptico y dinámico que, a diferentes escalas, abordan la mediterraneidad como rasgo más característico del clima. A escala regional cabe destacar las obras de Capel y Andújar (1978), Capel (1987), Pita (1987), Rodrigo \& Esteban-Parra (1994), Pita et al. (1999) y Rodrigo et al. (2012). A nivel provincial sobresalen las publicaciones de Bosque (1957) y Capel (1977a). Mientras que, entre los análisis comarcales resaltan los trabajos de Due (1959), Capel (1975, 1977b, 1978), Castillo (1981, 1985), Valle (1982), Frontana (1984), Pita et al. (1985), Olmedo-Cobo y Villacreces (2008) y Oliva y Gómez-Ortiz (2012). Sin embargo, son escasas las propuestas de sistematización del mosaico climático de Andalucía, destacando la clasificación genética regional de Castillo (1989) a partir de los tipos de tiempo $y$, en el marco de estudios comarcales de paisaje, las clasificaciones de Jiménez (1991), Ibarra (1993), Gómez-Zotano (2006) y Gómez-Zotano y Riesco-Chueca (2010).

Ante la carencia de clasificaciones regionales del clima mediterráneo en general, y de Andalucía en particular, en esta investigación se realiza, por primera vez, una identificación, clasificación y caracterización climática de carácter semiautomática e interescalar, de tipo empírico objetivo. Como principal resultado se presenta la cartografía y la caracterización de 5 regiones y 21 tipos climáticos.

\section{Método}

La región de Andalucía, con una extensión de $87.597 \mathrm{~km}^{2}$, se localiza en el tercio sur de España $\left(36^{\circ}-38,5^{\circ} \mathrm{N} ; 1^{\circ}-8^{\circ} \mathrm{W}\right)$, en una encrucijada entre dos continentes (Europa y África) y dos masas de agua (océano Atlántico y mar Mediterráneo) (Figura № 1). 
Figura $N^{\circ} 1$

Ámbito de estudio
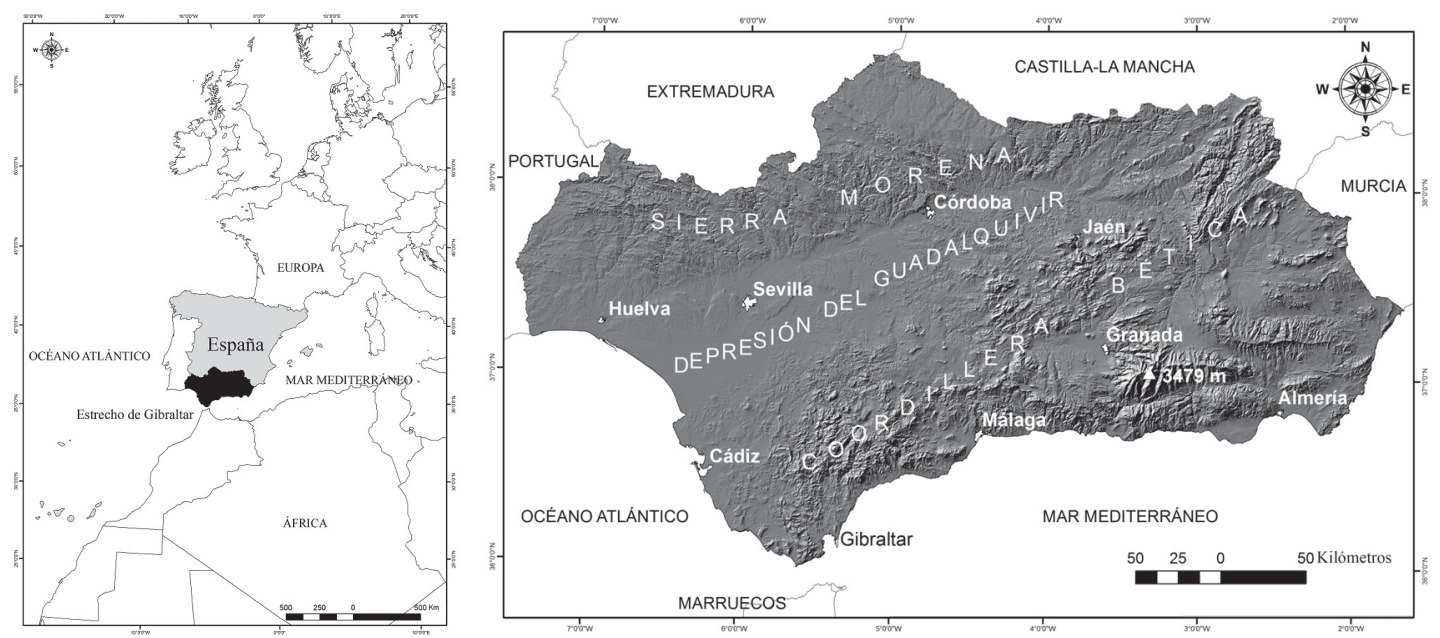

Fuente: Información vectorial contenida en la Red de Información Ambiental de Andalucía (REDIAM). Elaboración propia.

Las características generales del clima de Andalucía están directamente relacionadas con su ubicación en la zona meridional de la franja templada del Planeta, en la que ocupa una posición marginal respecto a la corriente en chorro polar. A su vez, las características subtropicales reinantes entre los $23^{\circ}$ y los $35^{\circ}$ de latitud -donde predominan células anticiclónicas- tienen un claro reflejo climático, ya que determinan, una acusada sequedad en la estación más cálida del año, el verano, que es la característica más definitoria del macroclima mediterráneo.

Estas circunstancias latitudinales y dinamo-atmosféricas son modificadas por factores geográficos, como la distribución de tierras y mares en su entorno, la accidentada orografía de la región y la disímil significación espacial de oceanidad y continentalidad en su territorio (Capel y Castillo, 1984; Castillo, 1989; Capel, 2000; Font, 2000).

\section{Proceso metodológico}

El proceso metodológico consta de tres fases principales: identificación, clasificación y caracterización. Se trata de un procedimiento automatizado, basado en la conjugación de la estadística multivariante y el criterio ex- perto, con la finalidad de obtener resultados robustos, reproducibles y representativos.

Para el desarrollo de la fase de identificación se requiere, como paso previo la elección, recopilación y preparación de las variables climáticas que la fundamentan. Las variables que se han elegido se citan a continuación: Temperatura media anual, Temperatura mínima anual, Temperatura mínima mensual, Temperatura máxima anual, Temperatura máxima mensual, Precipitación anual, Precipitación mensual, Evapotranspiración, Insolación real, Índice de continentalidad, Índice de aridez. Todas estas variables provienen de datos tomados en el período 1971-2000/2008, salvo el índice de continentalidad, que proviene de datos del período 1961-1990. Al respecto, se ha considerado conveniente definir el carácter oceánico, semioceánico, semicontinental y continental de los distintos tipos climáticos de la región según los umbrales que aparecen en el Cuadro $\mathrm{N}^{\circ} 1$.

Los datos de las variables meteorológicas corresponden a la red de estaciones principales y secundarias de la Agencia Estatal de Meteorología de España (AEMET). Esta red cuenta con más de 900 puntos de medición 
Cuadro $\mathrm{N}^{\circ} 1$

Índice de continentalidad para los tipos climáticos de Andalucía

\begin{tabular}{|l|r|r|r|}
\hline \multirow{2}{*}{ Climas } & \multicolumn{3}{|c|}{ Índice de continentalidad } \\
\cline { 2 - 4 } & \multicolumn{1}{|c|}{ Rango Medio } & \multicolumn{1}{c|}{ Rango Máximo } & \multicolumn{1}{c|}{ Rango Mínimo } \\
\hline Oceánicos & $12,6-14,4$ & 15,7 & 11,3 \\
Semioceánicos & $14,2-15,7$ & 18,2 & 12,7 \\
Semicontinentales & $15,0-17,8$ & 20,6 & 13,2 \\
Continentales & $16,6-19,6$ & 21,8 & 14,0 \\
\hline
\end{tabular}

Fuente: Adaptación a partir de Rivas-Martínez (2011).

activos en Andalucía, que comprenden estaciones automáticas, semiautomáticas y manuales de primer y segundo orden. Estas estaciones cubren adecuadamente todo el territorio (Figura $N^{\circ}$ 2) y recogen información de todos aquellos parámetros meteorológicos de interés climatológico: las estaciones meteorológicas automáticas ofrecen datos de viento, humedad, temperatura, precipitación y presión atmosférica; la red de estaciones principales combina sistemas manuales y automáticos, y registra las variables precipitación, temperatura del aire, humedad del aire, temperatura del suelo, radiación solar, insolación y evaporación; en la red de estaciones secundarias (manuales) se mide temperatura del aire y/o precipitación. Los datos son medidos en las condiciones estándar y con el instrumental oficial que, en ambos casos, recomienda la Organización Meteorológica Mundial, y son sometidos a validación por parte de personal experto para detectar cualquier error en las distintas medidas. Su fiabilidad es, por tanto, indudable, habiéndose empleado en distintas obras climáticas de referencia, como el Atlas Climático Ibérico (2011). Las variables seleccionadas y recopiladas se encuentran disponibles, previa solicitud, en el repositorio de información ambiental de la Red de Información Ambiental de Andalucía, de la Consejería de Medio Ambiente y Ordenación del Territorio de la Junta de Andalucía. Para adaptar las variables, se han estandarizado en valores de 0 a 1.000 .

Figura $\mathrm{N}^{\circ} 2$

Distribución de estaciones meteorológicas de referencia en el ámbito de estudio

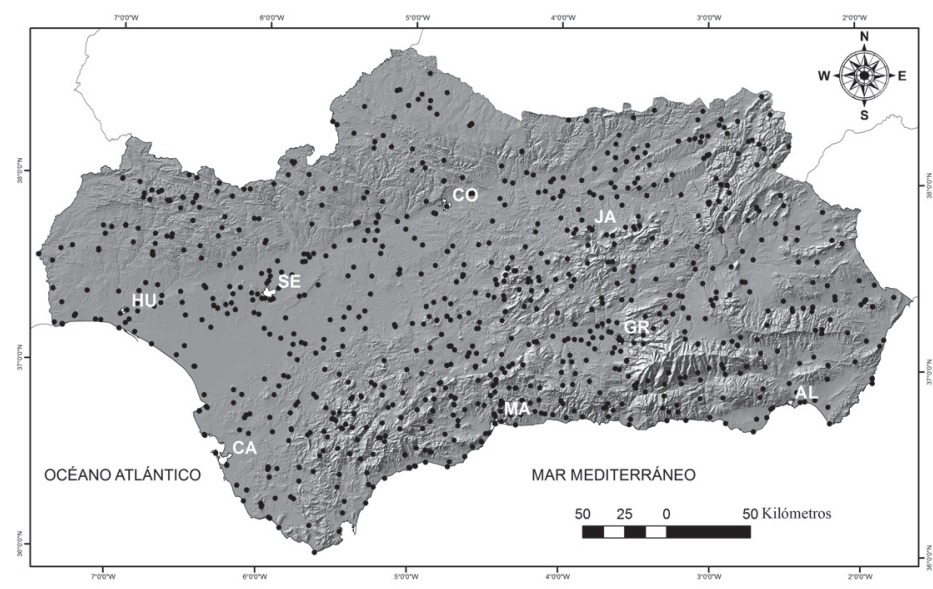

Fuente: REDIAM. Elaboración propia. 
En la fase de identificación se implementa un procedimiento semiautomático, a partir de estadística multivariante. En concreto, se ha empleado un sistema de doble análisis de clasificación, utilizado comúnmente en teledetección (Chuvieco \& Congalton, 1988; Salas y Chuvieco, 1995). El primero de los análisis antedichos ha consistido en una clasificación no supervisada, o clasificación a ciegas, en la que las variables estandarizadas se han sometido al algoritmo de clasificación ISODATA (Envi 4.6). Se trata de un análisis de clasificación restringido (el número de clases en la que se estructura la muestra es definido previamente por el usuario) y de reagrupamiento, ya que realiza un primer agrupamiento que se va refinando iterativamente. Como resultado de dicho análisis, se obtienen una serie de Grupos de referencia.

La reflexión del experto, en relación a la distribución geográfica, composición y adecuado agrupamiento de los Grupos de referencia, ha permitido la identificación de las Regiones climáticas de Andalucía.

El segundo análisis de clasificación, en este caso de tipo supervisado, tiene por objetivo la identificación de los Tipos climáticos de Andalucía a partir de las Regiones climáticas previamente identificadas. Este análisis consiste en clasificar una muestra de la que se tienen patrones predefinidos o una clasificación previa, ya sea por conocimiento experto, o por la obtención de una clasificación no supervisada. En la identificación de tipos climáticos, se ha utilizado como patrón a los Grupos de referencia y a las Regiones climáticas. Dicho patrón se introduce en la clasificación supervisada, a través de la elección de verdades terreno: zonas identificadas inequívocamente como pertenecientes a una categoría determinada, en este caso a un tipo climático. A partir de las verdades terreno y de las variables climáticas estandarizadas, el clasificador obtiene una nueva clasificación que posteriormente se hace extensible a todo el territorio. El clasificador que se ha utilizado en esta ocasión ha sido Minimum distance (ENVI 4.5). De la clasificación supervisada se han obtenido los tipos climáticos previos. Estos se han sometido a un filtrado y a un depurado experto, tras los cuales se han identificado los Tipos Climáticos definitivos.
Mediante la aplicación de un sistema de doble clasificación se persigue la máxima robustez en los resultados, tanto desde el punto de vista matemático como experto. Este sistema permite realizar un análisis exploratorio de los datos mediante la clasificación no supervisada, y un refinamiento posterior de los mismos a partir del conocimiento experto gracias a la clasificación supervisada. AqueIlos matices introducidos por criterio experto en el análisis de clasificación supervisada que no tengan refrendo estadístico no son recogidos en la clasificación resultante.

Como alternativas al proceso de doble clasificación se pueden considerar las dos fases que lo integran por separado. La clasificación no supervisada genera por sí sola resultados estadísticamente robustos, que sin embargo no siempre son reconocibles en la realidad. Por su parte, una clasificación supervisada sin un proceso previo no supervisado puede dar resultados demasiado subjetivos. Para ambos tipos de clasificaciones existen numerosos algoritmos. En cualquier caso, se considera que la combinación de ambos procedimientos en un sistema de doble clasificación ofrece los resultados más óptimos para cubrir los objetivos que se persiguen en esta investigación.

Por último, en el procedimiento para la caracterización de las regiones climáticas se señala, en primer lugar, su localización espacial en el conjunto geográfico de Andalucía. En segundo lugar, se realiza una aproximación general a su dinámica atmosférica mediante la sintetización de los elementos climáticos fundamentales (temperaturas y precipitaciones). Para la caracterización de los tipos climáticos se ha considerado su distribución geográfica y se ha realizado un análisis de sus rasgos climáticos más definitorios, particularizando los regímenes termométricos y pluviométricos

\section{Identificación, clasificación y caracterización climática de Andalucía}

\section{Escala regional}

Se han identificado cinco regiones climáticas para el conjunto de Andalucía. Aten- 
diendo a los factores y elementos climáticos determinantes, se propone la siguiente clasificación: región de climas costeros, región de climas de interior, región de climas de media montaña, región de climas de alta montaña y región de climas del sudeste (Figura $\mathrm{N}^{\circ} 3$ ).

Figura $\mathrm{N}^{\circ} 3$

Clasificación regional de los climas de Andalucía

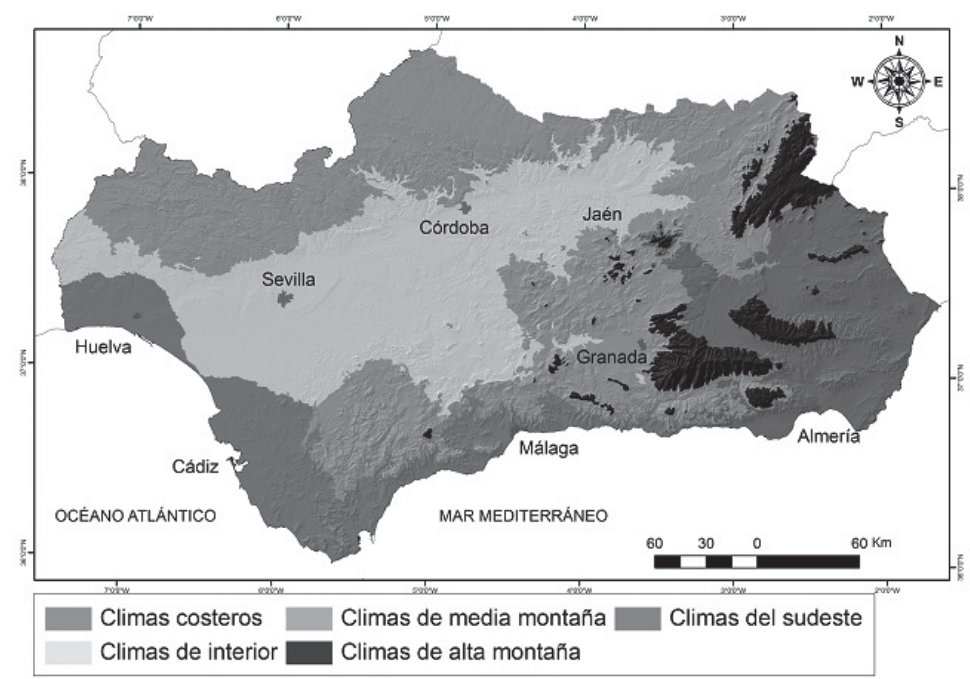

Fuente: Elaboración propia. Capas vectoriales de referencia: REDIAM

Las pricipales características de cada una de estas regiones se detallan a continuación:

\section{Región de climas costeros}

Se corresponde con la franja costera atlántica y mediterránea occidental de Andalucía. Con una extensión de 10.259 km², comprende un intervalo altitudinal de 0 a 400-600 metros sobre el nivel del mar (msnm). Su clima es de carácter templado, subhúmedo-húmedo aunque localmente seco, de elevada oceanidad y baja continentalidad.

Presenta un régimen térmico temperado -sin calores extremos prolongados ni episodios rigurosos de frío-, que se caracteriza por temperaturas medias anuales de $15^{\circ} \mathrm{C}$ a $19^{\circ} \mathrm{C}$; a dicha templanza también contribuye, en la franja mediterránea de la región, el abrigo orográfico frente a las corrientes frías septentrionales. La pluviosidad alcanza valores medios anuales de 600 a 1.000 mm, si bien existen acusadas diferencias internas, regis- trándose hasta 1.500 mm/año en torno al estrecho de Gibraltar, frente a mínimos de 415 $\mathrm{mm} / \mathrm{año}$ en el extremo oriental. El máximo pluviométrico es marcadamente tardootoñal e invernal, como consecuencia del desplazamiento meridional del vórtice circumpolar, desencadenante de vientos "ábregos" de S-SW húmedos, templados y de gran capacidad higrométrica. De otro lado, la sequedad estival, propia del clima mediterráneo, se ve atenuada por la influencia marítima (brisas, brumas, rocíos).

\section{Región de climas de interior}

Se desarrolla, en gran medida, por las depresiones del Guadalquivir y de Antequera. Su extensión es de $25.431 \mathrm{~km}^{2}$ y comprende un rango altitudinal de 50 a 500 msnm. Su clima es templado-cálido, seco-subhúmedo (progresivamente menos húmedo hacia el interior), con una neta disminución de la oceanidad y un notable aumento de la continentalidad de oeste a este. 
Su régimen térmico presenta valores medios anuales de $14^{\circ} \mathrm{C}$ a $19^{\circ} \mathrm{C}$ que resultan de estaciones bien contrastadas por el alejamiento gradual respecto al mar, y las configuraciones báricas estivales que dificultan la influencia atlántica a través del valle del Guadalquivir. Estas circunstancias favorecen veranos muy calurosos y prolongados e inviernos frescos con heladas ocasionales. El régimen pluviométrico oscila entre 800 $\mathrm{mm} / \mathrm{año}$ en exposiciones a barlovento, y 400 $\mathrm{mm} / \mathrm{año}$ a sotavento de los flujos atlánticos. Frente al máximo otoño-invernal, inducido por la frecuencia de los vientos zonales, el acusado mínimo estival mediterráneo determina, conjuntamente con las altas temperaturas, que la estación veraniega sea extremadamente seca.

\section{Región de climas de media montaña}

Ocupa la totalidad de Sierra Morena y de la cordillera Bética en el intervalo altitudinal comprendido entre 400 y $1.400-1.600$ msnm. Con una superficie de $35.021 \mathrm{~km}^{2}$, esta región es la más extensa de todas las identificadas en Andalucía. Su clima se puede catalogar como templado-frío y de precipitaciones desiguales. La compleja configuración orográfica de la región genera modificaciones sustanciales en los efectos de la circulación atmosférica.

Así, el régimen térmico es notablemente contrastado entre el interior, marcado por veranos cálidos e inviernos relativamente fríos, y las sierras cercanas al litoral, mucho más temperadas, lo que determina un amplio rango de la temperatura media anual $\left(11^{\circ} \mathrm{C}\right.$ a $18^{\circ} \mathrm{C}$ ). Los valores pluviométricos oscilan entre 600 y 1.200 mm/año, con un máximo otoñal e invernal, y un acusado mínimo estival. Existen destacados contrastes entre los relieves sudoccidentales, que registran promedios anuales de lluvia de hasta 2.000 mm, en contraposición con los enclaves más orientales, con una indigencia pluviométrica que se manifiesta en valores medios en torno a $300 \mathrm{~mm}$ anuales.

\section{Región de climas de alta montaña}

Presenta una distribución cacuminal en la cordillera Bética, constituyendo la menor extensión de las regiones climáticas de Andalu- cía $\left(4.986 \mathrm{~km}^{2}\right)$. Su clima se puede catalogar como frío o muy frío dado el factor altitudinal (1.600 a 3.482 msnm), y de carácter seco a subhúmedo (localmente húmedo) y de elevada continentalidad.

Su régimen térmico se caracteriza por las bajas temperaturas, con promedios anuales que oscilan entre $2^{\circ} \mathrm{C}$ y $13^{\circ} \mathrm{C}$. Los inviernos son rigurosos, con temperaturas negativas que se prologan de 6 a 10 meses. Solo el trimestre estival se puede considerar como una estación templada, si bien los valores máximos absolutos, superiores a $25^{\circ} \mathrm{C}$, se limitan a las cotas más bajas. La pluviosidad es variable, en función de la orientación y la altitud. No obstante, esta disimetría decrece de noroeste a sureste. Así, los valores máximos, de hasta $1.100 \mathrm{~mm}$, se limitan a las vertientes occidentales, expuestas a barlovento, mientras que los mínimos (300 mm/año) se registran a sotavento de las cumbres más orientales. Su régimen presenta un máximo otoño-invernal, desplazado ligeramente hacia la primavera en los macizos del extremo noreste. El mínimo mediterráneo estival, junto con la elevada insolación del verano, determinan una acusada xericidad ambiental. En las cumbres más altas, la nieve es el meteoro más frecuente, permaneciendo una media de 8 a 12 meses en el tercio superior de Sierra Nevada.

\section{Región de climas del sudeste}

Esta región ocupa el tercio más oriental de Andalucía, con una extensión total de $11.834 \mathrm{~km}^{2}$. Presenta un desarrollo altitudinal que oscila entre 0 y 1.400 msnm. Su clima es de carácter templado, marcado por una acusada aridez - prevalece el ambiente semiárido- y una disímil continentalidad entre el interior y la costa.

El régimen térmico es muy contrastado, con valores medios anuales comprendidos entre $11^{\circ} \mathrm{C}$ y $19^{\circ} \mathrm{C}$. El interior presenta inviernos rigurosos, frecuentemente heladores, y calurosos veranos, mientras que la costa resulta mucho más templada. La pluviosidad es escasa, dada la situación de la región a sotavento de los vientos húmedos del W. Los valores medios anuales oscilan entre 250 y 450 $\mathrm{mm}$, si bien las zonas más secas solo reciben del orden de 150 mm/año. Excepcionalmente, los registros anuales se incrementan hasta 
$650 \mathrm{~mm}$ en las áreas de montaña. El régimen de precipitaciones presenta un destacado carácter torrencial, con un máximo otoñal muy marcado, un acusado mínimo estival junto a otro invernal secundario.

\section{Escala comarcal}

En las distintas regiones climáticas se han identificado y clasificado, a escala comarcal, un total de veintiun tipos climáticos (Figura $\left.N^{\circ} 4\right)$.

Figura $\mathrm{N}^{\circ} 4$

Clasificación comarcal de los climas de Andalucía

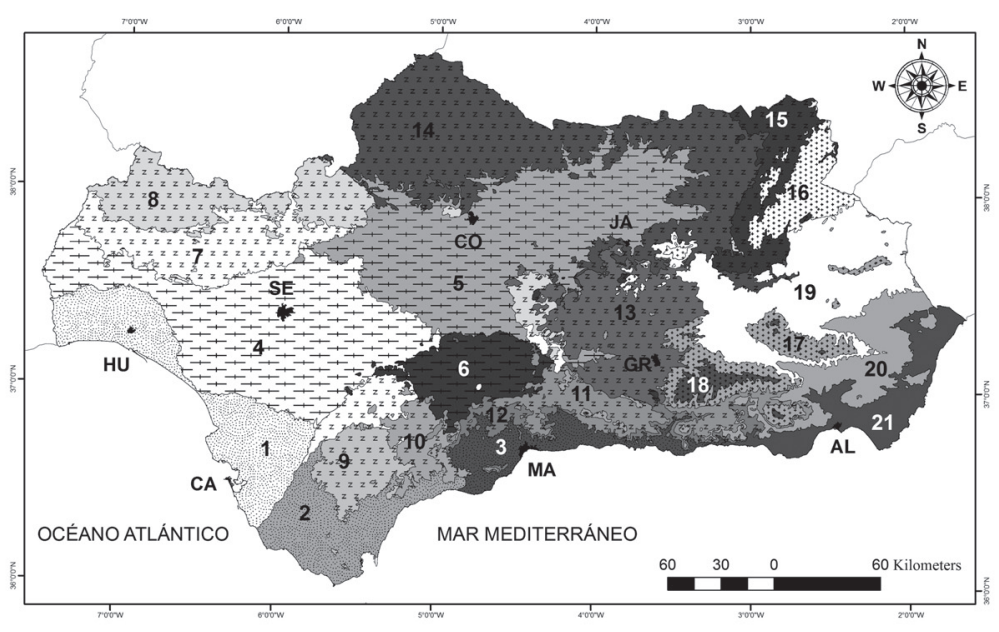

\begin{tabular}{|c|c|}
\hline \multicolumn{2}{|c|}{ Región de climas costeros } \\
\hline 1 & Clima mediterráneo oceánico subhúmedo del litoral de barlovento \\
\hline 2 & Clima mediterráneo de influencia marítima subhúmedo-húmedo del Estrecho de Gibraltar \\
\hline 3 & Clima mediterráneo seco-subhúmedo temperado del litoral de sotavento \\
\hline \multicolumn{2}{|r|}{ Región de climas de interior } \\
\hline 4 & Clima mediterráneo semi-oceánico del Bajo Guadalquivir \\
\hline 5 & Clima mediterráneo semi-continental del Medio Guadalquivir \\
\hline 6 & Clima mediterráneo semi-continental de las depresiones de Antequera y Padul \\
\hline \multicolumn{2}{|c|}{ Región de climas de media montaña } \\
\hline 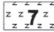 & Clima mediterráneo semi-oceánico (subhúmedo) del piedemonte peri-bético occidental \\
\hline 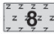 & Clima mediterráneo semi-oceánico (subhúmedo) de las sierras peri-béticas occidentales \\
\hline$x^{2}=9^{2} z^{2}$ & Clima mediterráneo oceánico (húmedo) de la Serranía de Ronda occidental \\
\hline${ }_{2}^{2}=10^{2}$ & Clima mediterráneo semi-oceánico de la Serranía de Ronda oriental \\
\hline${ }^{2}=11 z^{2}$ & Clima mediterráneo semi-continental de media montaña perimediterránea \\
\hline 12 & Clima mediterráneo temperado de valles y laderas perimediterráneas \\
\hline $13=$ & Clima mediterráneo continental de las sierras, pasillos y depresiones béticas centrales \\
\hline 14 & Clima mediterráneo continental de sierras y lomas circumbéticas orientales \\
\hline 15 & Clima mediterráneo continental de la media montaña prebética \\
\hline \multicolumn{2}{|c|}{ Región de climas de alta montaña } \\
\hline 6 & Clima mediterráneo frío de cimas prebéticas \\
\hline 17 & Clima mediterráneo frío de cimas béticas \\
\hline 18 & Clima mediterráneo periglaciar de altas cumbres béticas \\
\hline \multicolumn{2}{|r|}{ Región de climas del Sudeste } \\
\hline 19 & Clima continental mediterráneo seco-semiárido de los altiplanos y piedemontes orientales \\
\hline 20 & Clima mediterráneo semiárido-seco de sierras y piedemontes surorientales \\
\hline 21 & Clima mediterráneo semiárido-árido del litoral del extremo Sudeste \\
\hline
\end{tabular}

Fuente: Elaboración propia. Capas vectoriales de referencia: REDIAM 


\section{Región de climas costeros}

- Clima mediterráneo oceánico subhúmedo del litoral de barlovento

Se desarrolla en el litoral del golfo de Cádiz, englobando las Ilanuras y sectores acolinados inmediatos a la costa de Huelva, las marismas litorales del Guadalquivir y la campiña de Jerez y su entorno. Con una extensión de $4.936 \mathrm{~km}^{2}$, ocupa una franja altitudinal que comprende desde el nivel del mar hasta cotas de 150-200 m de altitud, con la excepción de la pequeña sierra de Gibalbín, que alcanza los $400 \mathrm{msnm}$. Se trata de un clima con una fuerte componente oceánica ligada a los vientos del W, que resultan determinantes para explicar su carácter templado y poco extremado y el ambiente subhúmedo que prevalece buena parte del año, lo que conlleva unos bajos índices de continentalidad, comprendidos entre 11,5 y 15 .

La temperatura media anual oscila entre $16,1^{\circ} \mathrm{C}$ y $18,8^{\circ} \mathrm{C}$, lo que representa los valores más elevados de toda la región de climas costeros. Los promedios de las máximas anuales alcanzan los $25^{\circ} \mathrm{C}\left(22^{\circ} \mathrm{C}\right.$ como extremo inferior), lo que se ve favorecido por la alternancia estival de los vientos marítimos con flujos mucho más cálidos procedentes del interior; los valores medios de los registros mínimos son particularmente templados, no bajando de $10^{\circ} \mathrm{C}$ en los enclaves más fríos $\left(14,5^{\circ} \mathrm{C}\right.$ de extremo superior), destacando que en invierno se ven comúnmente libres de temperaturas negativas debido a su posición latitudinal, longitudinal y la proximidad de la costa.

La precipitación media anual oscila entre 500 y 900 mm, concentrada mayoritariamente en los meses de otoño e invierno, época en la que la incidencia de las depresiones de frente polar es mayor. La creciente influencia de la subsidencia subtropical a medida que avanza la primavera determina la práctica ausencia de precipitaciones entre junio y septiembre.

- Clima mediterráneo de influencia marítima subhúmedo-húmedo del estrecho de Gibraltar

Se corresponde con el litoral del estrecho de Gibraltar y su entorno climático, lo que comprende las Ilanuras y campiñas centroorientales de la provincia de Cádiz, el extremo occidental de la provincia de Málaga (valles del Guadiaro y Genal) y las sierras litorales de Luna, Ojén, Montecoche, del Niño y Blanquilla. Con una extensión de 3.269 $\mathrm{km}^{2}$, presenta un gradiente altitudinal comprendido entre 0 y 400-600 msnm. El clima del estrecho de Gibraltar es uno de los más particulares de Andalucía por la alternancia durante todo el año de los vientos marinos de componente $\mathrm{E}$ y $\mathrm{W}$, que lo caracterizan como un tipo muy atemperado de carácter subhúmedo-húmedo y elevada oceanidad, que presenta consecuentemente los menores índices de continentalidad -11,3 a 14,3-de toda Andalucía.

La referida temperie oceánica determina temperaturas medias anuales comprendidas entre $14,5^{\circ} \mathrm{C}$ y $18,5^{\circ} \mathrm{C}$, que representan los extremos más bajos de toda la región. Los promedios anuales de las máximas alcanzan los $23,5^{\circ} \mathrm{C}$ en los sectores más cálidos, bajando a $17,5^{\circ} \mathrm{C}$ en las sierras litorales de mayor altitud, mientras que los registros mínimos anuales oscilan entre $10,7^{\circ} \mathrm{C}$ y $15^{\circ} \mathrm{C}$. Los valores absolutos estivales e invernales son muy contenidos.

Las precipitaciones oscilan entre 700 y 1.500 mm/año, con un máximo pluviométrico dilatado que ocupa buena parte del otoño e invierno; desde finales de primavera se impone una marcada sequedad, que se prolonga todo el verano, lo que caracteriza un periodo estival típicamente mediterráneo. Este régimen, asociado de manera general a la circulación zonal del $\mathrm{W}$, también es resultado de la incidencia de los vientos del E, especialmente significativa en las vertientes montañosas de barlovento, que presentan marcados gradientes pluviométrico positivos y una elevada frecuencia de nieblas de retención orográfica causantes de precipitaciones ocultas.

- Clima mediterráneo seco-subhúmedo temperado del litoral de sotavento

Aparece en la franja costera mediterránea central (provincias de Granada y Málaga) y en las inmediatas Ilanuras, valles y estribaciones montañosas de influencia litoral, hasta altitudes de 400-600 msnm, abarcando una ex- 
tensión de $2.054 \mathrm{~km}^{2}$. Es un clima que va de seco a subhúmedo, que adquiere un carácter costero debido a la incidencia atemperante de los vientos tanto mediterráneos como atlánticos, lo que a su vez favorece unos bajos índices de continentalidad, comprendidos entre 12,5 y 15 .

El influjo marítimo y el abrigo orográfico del cinturón montañoso que circunda por el norte este sector, y que lo aísla de los vientos invernales de procedencia septentrional, determinan que el régimen térmico sea suave todo el año, caracterizado por temperaturas medias anuales que oscilan entre $15^{\circ} \mathrm{C}$ y $18,7^{\circ} \mathrm{C}$. Los valores promedio de las máximas están comprendidos entre $19,5^{\circ} \mathrm{C}$ y $24,7^{\circ} \mathrm{C}$; los registros medios anuales de las mínimas varían entre $10^{\circ} \mathrm{C}$ y $13,7^{\circ} \mathrm{C}$, que en este caso representan los extremos más bajos de la región. La antedicha configuración orográfica favorece máximas estivales puntuales muy elevadas -de hasta $45^{\circ} \mathrm{C}$ - por el efecto Foehn que experimentan los vientos de procedencia interior (especialmente de W-NW); por su parte, las heladas invernales son puntuales $y$ de baja intensidad, quedando restringidas a las zonas más elevadas.

La pluviosidad de este clima es la más baja de toda la región al tratarse de un ámbito desarrollado predominantemente a sotavento de la componente zonal del W. Los promedios anuales oscilan entre los $415 \mathrm{~mm}$ del litoral más oriental y los $850 \mathrm{~mm}$ de las vertientes montañosas mejor orientadas a los vientos de S-SW y a los irregulares flujos del $E$, cuya recurrencia se relaciona con el complejo régimen eólico del mar de Alborán. Su régimen presenta un máximo otoñal, de marcada torrencialidad, decreciente paulatinamente hacia el invierno y la primavera, mientras que los meses estivales son extremadamente secos.

\section{Región de climas de interior}

- Clima mediterráneo semioceánico secosubhúmedo del bajo Guadalquivir

Se extiende a lo largo de $10.765 \mathrm{~km}^{2}$ por las Ilanuras, campiñas y marismas no litorales del bajo Guadalquivir, alcanzado las primeras estribaciones del piedemonte de Sierra Morena hacia el norte y de la cordillera Bética hacia el sur, en un intervalo altitudinal comprendido entre 20-50 y 150-200 msnm. Se trata de un clima templado-cálido y subhúmedo en general, aunque relativamente seco de manera local. Al desarrollarse en ámbitos progresivamente más interiores y elevados, presenta un decrecimiento paulatino de la oceanidad hacia el este, y un aumento de los índices de continentalidad desde 12,5 hasta 17, de ahí su catalogación como clima semioceánico.

Su régimen térmico se caracteriza por registros medios anuales que oscilan entre $16,5^{\circ} \mathrm{C}$ y $18,5^{\circ} \mathrm{C}$, los más elevados de la región de climas de interior. La temperatura media de las máximas se eleva hasta $25,5^{\circ} \mathrm{C}$ $\left(22,5^{\circ} \mathrm{C}\right)$, lo que representa también el promedio más alto para el conjunto de Andalucía. Cabe destacar que el periodo estival es muy caluroso, dada la escasa influencia oceánica, superándose con frecuencia los $40^{\circ} \mathrm{C}$, y con registros absolutos superiores a $45^{\circ} \mathrm{C}$. Los promedios mínimos anuales oscilan entre $9,8^{\circ} \mathrm{C}$ y $12,3^{\circ} \mathrm{C}$-los más elevados de la región-, resultado de inviernos poco rigurosos, con escasos días de helada, y de valores estivales elevados con frecuentes "noches tropicales" $\left(>20^{\circ} \mathrm{C}\right)$.

La pluviosidad es moderada, con valores de precipitación media anual que oscilan entre 510 y $780 \mathrm{~mm}$. Su régimen se asocia casi por completo a los flujos húmedos de W-SW, cuya incidencia se ve favorecida por la ausencia de obstáculos orográficos. El máximo pluviométrico se prolonga desde noviembre a enero-febrero. La primavera está marcada por precipitaciones irregulares. $Y$ en verano apenas se recogen precipitaciones, al menos, dos meses y medio.

- Clima mediterráneo semicontinental secosubhúmedo del medio Guadalquivir

Se desarrolla en el valle medio del Guadalquivir y piedemontes inmediatos, tanto de Sierra Morena al norte como de la cordillera Bética al sur, así como en el extremo occidental de la depresión de Granada. Su extensión es de 11.836 km², y comprende un intervalo altitudinal de 100 a 400-500 msnm. Es un clima templado de seco a subhúmedo, con unos acentuados índices de continentalidad, que oscilan entre 15 y 20,5 -los más 
elevados de la región-. Sin embargo, todavía acusa la temperie que aportan los vientos del W en su desplazamiento por el valle, por lo que, en su conjunto, se considera un tipo semicontinental.

Las temperaturas medias anuales oscilan entre $15^{\circ} \mathrm{C}$ y $18^{\circ} \mathrm{C}$, con unos promedios de las máximas elevados, de hasta $25^{\circ} \mathrm{C}\left(22^{\circ} \mathrm{C}\right)$. Las temperaturas mínimas medias descienden hasta $7,8^{\circ} \mathrm{C}$ y no superan $\operatorname{los} 11,5^{\circ} \mathrm{C}$, siendo estos los extremos inferiores más bajos de la región. Este régimen térmico viene definido por estaciones equinocciales templadas, por calurosos veranos, donde la barrera de los $40^{\circ} \mathrm{C}$ se supera con facilidad -con máximos absolutos de $48^{\circ} \mathrm{C}$ y numerosas noches tropicales-y por inviernos frescos, donde el número de jornadas con mínimas negativas puede alcanzar la cincuentena.

La pluviosidad es media, decreciente hacia el interior como consecuencia lógica de la progresiva pérdida higrométrica de las masas de aire atlánticas en su desplazamiento al este. Los valores máximos se aproximan a $800 \mathrm{~mm} / \mathrm{año}$ en los piedemontes noroccidentales, mientras que los sectores Ilanos más interiores, algunos incluso en posición relativa de sombra de lluvia, solo reciben 435 $\mathrm{mm} / \mathrm{año}$ como promedio. Su régimen es típicamente mediterráneo, es decir, a la extrema sequedad estival se contrapone un máximo otoño-invernal relacionado con la circulación zonal.

- Clima mediterráneo semicontinental secosubhúmedo de las depresiones de Antequera y Padul

Aparece en la depresión de Antequera y en los piedemontes y vertientes basales de las sierras periféricas (Loja, Camarolos, Archidona y estribaciones nororientales de la serranía de Ronda), así como en la pequeña cuenca intramontañosa de Padul. Su extensión se limita a $2.829 \mathrm{~km}^{2}$, y abarca un intervalo altitudinal de 300 a 800-1.000 msnm. Se trata de un clima templado, seco a subhúmedo, relativamente continentalizado, dada su lejanía al mar y a su configuración fisiográfica semicerrada. Estas circunstancias conllevan a índices de continentalidad que oscilan entre 14 y 16,5 , por lo que se considera este clima como un tipo semicontinental.
Los valores de temperatura media anual quedan comprendidos entre $14,3^{\circ} \mathrm{C}$ y $18^{\circ} \mathrm{C}$, con unos promedios de las máximas de $20^{\circ} \mathrm{C}$ a $24^{\circ} \mathrm{C}$. En ambos casos, se trata de los registros medios más bajos de la región. Las temperaturas medias anuales de las mínimas oscilan entre $8,5^{\circ} \mathrm{C}$ y $12^{\circ} \mathrm{C}$. Los veranos son calurosos -con máximas puntuales por encima de $40^{\circ} \mathrm{C}-$, los inviernos resultan relativamente fríos -con frecuentes heladas de inversión en zonas llanas- y las estaciones intermedias son templadas aunque relativamente fugaces.

La pluviometría media anual es la más baja del contexto regional, oscilando entre unos 450 y 750 mm. Los valores más bajos se registran en las zonas Ilanas, especialmente en aquellos emplazamientos a sotavento relativo de la circulación zonal. Mientras que las vertientes serranas y piedemontes más elevados y mejor expuestos a los vientos atlánticos recogen los valores más elevados. La mediterraneidad también caracteriza su régimen pluviométrico, lo que implica una extrema sequedad estival como contrapunto al periodo de mayor humedad, coincidente con los meses cercanos al solsticio de invierno.

\section{Región de climas de media montaña}

- Clima mediterráneo semioceánico subhúmedo-húmedo del piedemonte peri-bético occidental

Se extiende a lo largo de $5.032 \mathrm{~km}^{2}$ por los piedemontes occidentales de Sierra Morena y septentrionales de la serranía de Ronda, en contacto con la depresión del Guadalquivir. Se trata de un clima suave, templado y subhúmedo (húmedo localmente), marcado por la influencia oceánica y la modesta altitud de las tierras por las que se distribuye, comprendidas en el intervalo 100 a 400-600 msnm. La pérdida de templanza atlántica hacia el interior, aunque provoca una progresiva continentalización -índices máximos de continentalidad de 18 (13)-, ha sido catalogada como semioceánica.

Las temperaturas medias anuales son relativamente homogéneas en todo el ámbito, a pesar del gradiente altitudinal, quedando comprendidas entre $15,1^{\circ} \mathrm{C}$ y $18,4^{\circ} \mathrm{C}$. Los valores medios de las máximas son elevados, 
oscilando entre $20,5^{\circ} \mathrm{C}$ y $24,9^{\circ} \mathrm{C}$, lo que hay que relacionar en parte con la escasa influencia marítima en verano, estación que, en consecuencia, resulta bastante calurosa. Ambos promedios son los más altos de toda la región de climas de media montaña. Las medias anuales de las mínimas son contenidas, no bajando de $8,9^{\circ} \mathrm{C}$ y $\sin$ superar $\operatorname{los} 12,5^{\circ} \mathrm{C}$, destacando la suavidad del invierno, debido a la influencia oceánica que, entre otras cosas, limita el número de heladas a unos pocos días al año.

La pluviosidad es variable, con promedios anuales que oscilan entre 630 y $1.170 \mathrm{~mm} /$ año, como consecuencia de la altitud y la compartimentación del relieve. Su pluviometría está directamente relacionada con la exposición favorable a las masas de aire oceánicas, ya que estas no encuentran en su desplazamiento barreras orográficas. EI máximo de precipitaciones se concentra entre noviembre y enero-febrero; a una primavera irregular le sucede un periodo estival muy seco, que especifica a este clima como típicamente mediterráneo.

- Clima mediterráneo semioceánico subhúmedo-húmedo de las sierras peribéticas occidentales

Se desarrolla en el tercio oeste de Sierra Morena (provincias de Huelva y Sevilla) y, con menor significación, en las estribaciones occidentales de las sierras subbéticas de Córdoba, abarcando un total de $4.479 \mathrm{~km}^{2}$, en un intervalo altitudinal de 400 a $900 \mathrm{msnm}$. Es un clima templado-fresco de carácter subhúmedo y, puntualmente, húmedo, en el que la influencia atlántica todavía es trascendente, de ahí su especificación como un tipo semioceánico a pesar de que presenta índices de continentalidad moderados (entre 15 y 19) que, en este caso, hay que relacionar en mayor medida con la altitud del ámbito que con el neto carácter continental de su dominio.

El régimen térmico se caracteriza por su moderación, con temperaturas medias anuales que oscilan entre $12,5^{\circ} \mathrm{C}$ y $17^{\circ} \mathrm{C}$, cuyo gradiente atiende básicamente al factor altitudinal. Los promedios de las máximas y de las mínimas quedan comprendidos, respectivamente, entre $19^{\circ} \mathrm{C}$ y $24^{\circ} \mathrm{C}$, y $5,8^{\circ} \mathrm{C}$ y $10,7^{\circ} \mathrm{C}$.
Las precipitaciones son abundantes en el extremo noroccidental, con promedios de hasta $1.175 \mathrm{~mm} / \mathrm{año}$ en las zonas más elevadas, donde se acusa un neto incremento pluviométrico por cuestiones orográficas. En contraposición, las zonas bajas más orientales -las más interiores $y$, en consecuencia, las menos afectadas por los flujos húmedos de W-SW-, registran valores medios mínimos de $680 \mathrm{~mm} / a$ ño. El régimen es típicamente mediterráneo, aunque con las particularidades propias de la influencia atlántica. El máximo pluviométrico se concentra entre mediados del otoño y finales del invierno, mientras que las precipitaciones se reducen drásticamente en el periodo estival junio-agosto, que representa en el mejor de los casos un $5 \%$ del total.

- Clima mediterráneo oceánico húmedohiperhúmedo de la serranía de Ronda occidental

Aparece en la mitad occidental de la serranía de Ronda -macizos de Grazalema, Ubrique y Líbar- y en las cumbres más elevadas cercanas al estrecho de Gibraltar (sierras del Aljibe, del Niño y de Luna). Con una extensión de $1.740 \mathrm{~km}^{2}$, su desarrollo altitudinal queda comprendido entre $400 \mathrm{y}$ $1.600 \mathrm{msnm}$. Es un clima templado de media montaña que destaca por ser el tipo más húmedo -alcanzando el umbral hiperhúmedo-, debido a la conjunción de orografía, altitud y exposición a los vientos atlánticos zonales. En consecuencia, es marcadamente oceánico, alcanzando los índices de continentalidad más bajos de la región (entre 12 y 15,3).

Las temperaturas medias son suaves, moderadamente contrastadas debido al gradiente altitudinal, que provoca diferencias de $7^{\circ} \mathrm{C}$ en los promedios anuales, que quedan comprendidos entre $18^{\circ} \mathrm{C}$ y $11^{\circ} \mathrm{C}$. En cualquier caso, estos valores resultan de veranos e inviernos poco extremados, y de estaciones intermedias de notable suavidad, que, en conjunto, deparan registros medios anuales de las máximas entre $15,5^{\circ} \mathrm{C}$ y $23,5^{\circ} \mathrm{C}$ y de las mínimas entre $6,5^{\circ} \mathrm{C}$ y $13,6^{\circ} \mathrm{C}$. En el segundo caso, se trata de los promedios más altos de toda la región. El número de heladas invernales solo es reseñable en las cumbres superiores a 1.200 msnm, mientras que los registros absolutos estivales difícilmente superan $\operatorname{los} 38^{\circ} \mathrm{C}$. 
En el dominio de este clima aparecen los máximos pluviométricos de Andalucía, con valores medios cercanos a $2.000 \mathrm{~mm} / \mathrm{año} \mathrm{en}$ la sierra de Grazalema, macizo en el que los registros absolutos superan los $4.300 \mathrm{~mm} /$ año, los $1.000 \mathrm{~mm} / \mathrm{mes}$ y los $300 \mathrm{~mm} /$ día; el resto de tierras queda en torno o por encima de $1.000 \mathrm{~mm} / \mathrm{año}$. El régimen pluvial muestra un máximo que se prolonga desde el otoño hasta mediados de la primavera; las precipitaciones decaen drásticamente desde entonces, siendo el verano una estación de extrema indigencia pluviométrica, que es fiel reflejo del carácter mediterráneo de este clima.

- Clima mediterráneo semioceánico subhúmedo-húmedo de la serranía de Ronda oriental

Se corresponde con la zona oriental de la serranía de Ronda, macizos de Las Nieves, Tolox, Bermeja y extremo occidental de Mijas, distribución que comprende un intervalo altitudinal de 400 a 1.500 msnm y una extensión de $1.266 \mathrm{~km}^{2}$. Es un clima templadofresco y moderadamente húmedo gracias a la todavía relevante influencia oceánica. Sin embargo, como consecuencia de su posición, al este de la mitad occidental de la serranía, como por su altitud, el efecto temperante de los vientos atlánticos queda en cierta medida atenuado, lo que determina su catalogación como un tipo semioceánico -de modesta continentalidad (índices de 12,7 a 15,8)-.

El régimen térmico se caracteriza por valores medios anuales de $11^{\circ} \mathrm{C}$ a $17^{\circ} \mathrm{C}$, resultantes del contrastado desarrollo altitudinal. Los promedios de las máximas son los más bajos de toda la región $-15,7^{\circ} \mathrm{C}$ a $22,2^{\circ} \mathrm{C}-$, mientras que los registros de las mínimas son contenidos, oscilando entre $6,7^{\circ} \mathrm{C}$ y $11,9^{\circ} \mathrm{C}$. De estaciones equinocciales bien marcadas, los veranos solo resultan relativamente calurosos en cotas bajas del interior, mientras que los rigores invernales se dejan sentir en las zonas altas en forma de frecuentes días de heladas y ocasionales nevadas entre el final del otoño y el comienzo de la primavera.

La pluviosidad es variable, aunque en general resulta de moderada a notable, con registros medios anuales que oscilan entre 600 y $1.200 \mathrm{~mm} / \mathrm{año}$. Esta disimetría obedece a la influencia del relieve. El régimen pluviomé- trico presenta un máximo de otoño-invierno y un mínimo acusado de verano, cuyo origen anticiclónico subtropical vuelve a mostrar la naturaleza mediterránea de este clima.

- Clima mediterráneo semicontinental secosubhúmedo de media montaña perimediterránea

Comprende una serie de macizos montañosos béticos perimediterráneos que se desarrollan de oeste a este en el interior sur de las provincias de Málaga, Granada y este de Almería, entre los que destacan las sierras de Camarolos-Loja, Almijara-Tejeda y LújarLa Contraviesa, además de las estribaciones meridionales de Sierra Nevada. Ocupa una extensión de $2.502 \mathrm{~km}^{2}$ y se limita al intervalo altitudinal 800 a $1.400 \mathrm{msnm}$. Se trata de un clima de carácter suave, variablemente húmedo debido a la compleja orografía de su dominio, resultando en general de seco a subhúmedo. Se ve todavía afectado por la temperie del cercano mar Mediterráneo, especialmente en las sierras prelitorales meridionales, aunque la altitud determina su carácter semicontinental (índices de continentalidad de hasta 16,5).

Las temperaturas medias anuales son contenidas, con promedios que oscilan entre $11,5^{\circ} \mathrm{C}$ y $16,5^{\circ} \mathrm{C}$ debido al relieve y su compartimentación. Los registros medios de las máximas quedan comprendidos entre $16^{\circ} \mathrm{C}$ y $22,5^{\circ} \mathrm{C}$, y los valores anuales de las mínimas no bajan de $6^{\circ} \mathrm{C}$ y se elevan hasta $11,3^{\circ} \mathrm{C}$ en los enclaves menos continentales de cotas bajas. Los inviernos solo resultan relativamente rigurosos en zonas elevadas, donde las heladas son frecuentes; los veranos son cálidos aunque no calurosos.

La variable pluviosidad de este clima se explica por la disímil influencia que tienen los vientos húmedos del $\mathrm{W}$ en las vertientes de barlovento de las sierras más occidentales, donde los promedios más elevados alcanzan los 920 mm/año, respecto a ciertos enclaves orientales a baja altitud, desarrollados a sotavento, que solo recogen $260 \mathrm{~mm} / \mathrm{año}$ (valor mínimo de la región). El régimen de las precipitaciones, ciertamente torrencial, se concentra entre el otoño y la primera mitad del invierno. Las precipitaciones en primavera 
varían según el sector, en cualquier caso, dan lugar a un trimestre estival muy seco.

- Clima mediterráneo seco-subhúmedo temperado de valles y laderas perimediterráneas

Se limita a $1.178 \mathrm{~km}^{2}$ de los piedemontes y laderas de las sierras mediterráneas prelitorales de Mijas, Camarolos, Montes de Málaga, Cázulas, Lújar y La Contraviesa, así como a los valles de los ríos Guadalfeo y Adra. Por cuestiones de exposición orográfica su ombroclima oscila entre seco y subhúmedo. Además presenta una relativa bonanza térmica debido a su baja altitud, pues se desarrolla en cotas de entre 200 y 600 msnm, su orientación, predominantemente sur, y su carácter marítimo, ya que está claramente influenciado por el Mediterráneo. Se puede considerar un tipo de transición entre los continentales del interior y los oceánicos del litoral mediterráneo central de Andalucía; sus modestos índices de continentalidad -13 a $15,5-$ lo relacionan en mayor medida con los segundos.

El régimen térmico determina valores medios anuales de $14,5^{\circ} \mathrm{C}$ a $18,2^{\circ} \mathrm{C}$, resultantes de promedios de las máximas claramente relacionados con la baja altitud del ámbito, ya que oscilan entre $19,5^{\circ} \mathrm{C}$ y $24^{\circ} \mathrm{C}$, y de registros de las mínimas igualmente contenidas, quedando entre $8,5^{\circ} \mathrm{C}$ y $12,5^{\circ} \mathrm{C}$. Los valores extremos estivales e invernales son poco rigurosos como consecuencia de la acción reguladora del mar, lo que depara en general máximas y mínimas absolutas por debajo de $40^{\circ} \mathrm{C}$ y por encima de $0^{\circ} \mathrm{C}$, respectivamente.

Los promedios de precipitación media anual quedan comprendidos entre 930 y 350 $\mathrm{mm} / \mathrm{año}$, disimetría relacionada de nuevo con la distintiva orientación y exposición a los flujos zonales atlánticos. La altitud, determinante de gradientes pluviométricos positivos por retención orográfica, favorece que las zonas superiores sean las que registren mayores valores. El régimen pluvial presenta una notable torrencialidad, con un máximo marcadamente otoñal en la mitad oriental, alargándose hacia la primera mitad del invierno en el oeste; el verano es rotundamente mediterráneo con una ausencia casi absoluta de lluvia.
- Clima mediterráneo continental seco-subhúmedo de las sierras, pasillos y depresiones béticas centrales

Se desarrolla a lo largo de $4.836 \mathrm{~km}^{2}$ en la media montaña bética central, en cotas de entre 600 a $1.400 \mathrm{msnm}$, lo que comprende las sierras de Cabra, Parapanda, Moclín, Alta Coloma, Pandera y Alfaguara, y las Ilanuras de la depresión de Granada y del pasillo intramontañoso de Iznalloz-Moreda. Se trata de un clima templado-frío, de carácter seco a subhúmedo, con estaciones bien contrastadas debido a su desarrollo interior y aislado de la influencia oceánica, lo que determina que presente unos elevados índices de continentalidad, de hasta $21,3(14,6)$.

El régimen térmico se caracteriza por valores medios anuales comprendidos entre $11,5^{\circ} \mathrm{C}$ y $16^{\circ} \mathrm{C}$, con registros de las máximas de hasta $23,5^{\circ} \mathrm{C}\left(17,5^{\circ} \mathrm{C}\right)$ y de las mínimas que bajan a $4,8^{\circ} \mathrm{C}\left(9,5^{\circ} \mathrm{C}\right)$. Los promedios anual y de las mínimas son los más bajos de la región. Bajo estos parámetros térmicos generales, que hay que contextualizarlos en la lógica gradación altitudinal del dominio, las estaciones solsticiales resultan notablemente extremadas frente al carácter agradable aunque fugaz del otoño y de la primavera; son frecuentes los registros absolutos cercanos a $40^{\circ} \mathrm{C}$ y numerosas las jornadas de helada, tanto por inversión en las zonas deprimidas como por advección en las áreas montañosas.

Su pluviosidad es, en general, media aunque con diferencias apreciables fruto de la distinta exposición de sierras y cuencas intramontañosas a los vientos húmedos del W. Las vertientes más elevadas de barlovento alcanzan los 880 mm/año como promedio máximo; por el contrario, las Ilanuras interiores, alejadas de la retención orográfica y en sombra de lluvia, presentan una pluviometría media anual de $400 \mathrm{~mm}$, con valores mínimos

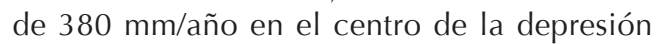
de Granada. El régimen de las precipitaciones muestra un máximo bien marcado entre noviembre y febrero, un repunte primaveral tras un mínimo relativo en marzo, y una casi absoluta sequedad durante el verano, lo que inequívocamente identifica a este clima como mediterráneo. 
- Clima mediterráneo continental seco-subhúmedo de sierras y lomas circumbéticas orientales

Se concentra en la parte central y oriental de Sierra Morena, y más aisladamente en otros macizos béticos igualmente encarados al valle del Guadalquivir (sierras de Jabalcuz, Mágina y Cazorla), así como en la depresión del Guadiana menor. Abarca una extensión de $11.485 \mathrm{~km}^{2}$ y un intervalo altitudinal de $400 \mathrm{a}$ $1.200 \mathrm{msnm}$. Es un clima medianamente seco, aunque localmente subhúmedo, y ciertamente extremado fruto de su posición interior y moderada altitud, lo que provoca que presente los índices de continentalidad más elevados de toda Andalucía, de hasta 21,8 (aunque solo de 15,5 en las zonas bajas más occidentales todavía afectadas por la oceanidad que penetra por el valle del Guadalquivir).

Las temperaturas medias anuales oscilan entre $13^{\circ} \mathrm{C}$ y $17,3^{\circ} \mathrm{C}$, con promedios de las máximas entre $19^{\circ} \mathrm{C}$ y $23,9^{\circ} \mathrm{C}$, y mínimas entre $6,6^{\circ} \mathrm{C}$ y $11,2^{\circ} \mathrm{C}$. Los veranos resultan calurosos, con máximas absolutas de hasta $40^{\circ} \mathrm{C}$, y los inviernos son relativamente fríos -con numerosas jornadas con mínimas bajo cero, especialmente en las más Ilanas-. Solo la canalización de masas de aire atlánticas por la cuenca del Guadalquivir logra atemperar en cierta medida estos extremos, especialmente en las zonas bajas abiertas al valle.

Los promedios de precipitación están comprendidos entre $450 \mathrm{~mm} / \mathrm{año}$ en enclaves interiores del norte y este (Los Pedroches y valle del Guadiana menor) y cerca de 800 mm/año en los emplazamientos más suroccidentales de Sierra Morena. El régimen de precipitaciones, claramente relacionado con la Circulación General del Oeste, presenta un máximo pluvial otoño-invernal, aunque con un mínimo relativo durante los meses fríos en las zonas más continentales, y otro, mucho más acusado y generalizado, en los meses estivales, periodo en el que solo cabe destacar la aparición de fenómenos convectivos aislados en el extremo noreste.

- Clima mediterráneo continental subhúmedo de la media montaña prebética

Se corresponde con las vertientes occidentales y meridionales del complejo monta- ñoso de Cazorla-Segura y con el extremo nororiental de Sierra Morena, dentro del rango altitudinal 500 a $1.200 \mathrm{msnm}$, abarcando un dominio de $2.499 \mathrm{~km}^{2}$. Es un clima templado-frío, de carácter subhúmedo en general, aunque localmente seco y puntualmente húmedo, cuyo emplazamiento interior y, por tanto, alejado de la influencia oceánica provoca un elevado grado de continentalidad, con índices máximos superiores a 21 (16).

Las temperaturas medias anuales oscilan entre $11,8^{\circ} \mathrm{C}$ y $16,5^{\circ} \mathrm{C}$, en respuesta a las diferencias altitudinales, si bien hay que señalar que, a una misma altitud, el extremo norte es más frío que el resto de la unidad por su cercanía a los extremados climas meseteños del interior ibérico. El carácter interior de estas tierras conlleva veranos calurosos, con extremos absolutos cercanos a $40^{\circ} \mathrm{C}$, lo que favorece promedios anuales de las máximas de hasta $23^{\circ} \mathrm{C}$ en las cotas inferiores $\left(17,5^{\circ} \mathrm{C}\right)$. Los valores medios de las mínimas quedan comprendidos entre los $5,5^{\circ} \mathrm{C}$ de las cotas más altas y los $10^{\circ} \mathrm{C}$ de los valles más abiertos al oeste. Cabe destacar el elevado número de días con mínimas negativas -de 20 a 50durante los meses fríos en buena parte del territorio.

La pluviosidad varía según la orientación barlovento-sotavento de las laderas, y por el contraste que induce la altitud. Las vertientes occidentales presentan promedios de hasta $1.070 \mathrm{~mm} / a$ ño en las zonas altas mientras que las tierras más meridionales y surorientales, que quedan a resguardo de los flujos del NW, ofrecen registros mínimos de $565 \mathrm{~mm} /$ año. Su régimen pluvial se caracteriza por un máximo de precipitación que se alarga desde mediados de otoño hasta principios o mediados de primavera; los meses estivales se caracterizan por una acusada sequedad.

4. Región de climas de alta montaña

- Clima mediterráneo frío subhúmedo de cimas prebéticas

Se desarrolla en las sierras del extremo noreste de la región (Cazorla, Segura, Castril y la Sagra) y en otros macizos interiores centro-orientales (Mágina, Valdepeñas, La Pandera y Jabalcuz). Ocupa una extensión de $1.788 \mathrm{~km}^{2}$, en un intervalo altitudinal com- 
prendido entre 1.200 y 2.100 msnm. Es un clima moderadamente frío y en general subhúmedo, que presenta los mayores índices de continentalidad de la región de climas de alta montaña -de hasta 21,2 (17)- debido a su altitud y posición interior lejos de la temperie oceánica.

Las temperaturas medias anuales oscilan entre $7,3^{\circ} \mathrm{C}$ y $13,5^{\circ} \mathrm{C}$ según el gradiente altitudinal, que también condiciona los promedios de las máximas y de las mínimas, que quedan comprendidos entre $13,1^{\circ} \mathrm{C}$ y $20,2^{\circ} \mathrm{C}$ y $1,6^{\circ} \mathrm{C}$ y $7,5^{\circ} \mathrm{C}$, respectivamente. Los modestos registros anuales de la mitad superior del ámbito vienen determinados por la suavidad estival, la frecuencia de jornadas invernales muy frías y los numerosos días de helada. El ambiente más templado corresponde al tercio inferior occidental, que es además la zona menos continental, y donde son frecuentes las jornadas estivales de relativo calor.

Las precipitaciones varían según la posición frente a los flujos atlánticos. Así, se alcanzan $1.150 \mathrm{~mm} / \mathrm{año}$ en zonas altas, mientras que en las laderas basales más orientales solo se recogen $470 \mathrm{~mm} / \mathrm{año}$. El gradiente pluviométrico positivo, asociado a la retención orográfica, decrece paulatinamente de oeste a este y de norte a sur. El régimen de las precipitaciones presenta un máximo otoño-invernal bien definido, con frecuentes nevadas, siendo este el clima donde las lluvias de primavera representan una mayor cuantía respecto del total en Andalucía. Más significativo aún es que, dentro de un verano inequívocamente mediterráneo, las precipitaciones estivales totalicen unos $100 \mathrm{~mm}$ en el trimestre junio-agosto en determinados enclaves nororientales, donde los fenómenos convectivos son relativamente frecuentes.

- Clima mediterráneo frío seco-subhúmedo de cimas béticas

Se distribuye a lo largo de $2.630 \mathrm{~km}^{2}$ en el intervalo altitudinal comprendido entre 1.400 y $2.000 \mathrm{msnm}$ de los macizos béticos de Almijara-Tejeda, Nevada, Huétor-Arana, Gádor y Baza-Filabres, además de en otras cumbres secundarias de la cordillera. Se trata de un clima relativamente frío, de carácter seco a subhúmedo, con un grado de continentalidad variable, aunque notable en general, con ín- dices máximos de 19 hacia el interior y mínimos de 14 en los enclaves más meridionales.

Los registros térmicos medios anuales oscilan entre $14^{\circ} \mathrm{C}$ y $8,7^{\circ} \mathrm{C}$ por las diferencias altitudinales; estos valores son los más elevados de la región climática de alta montaña. Los promedios anuales de las máximas y de las mínimas no sobrepasan los $13,5^{\circ} \mathrm{C}$ y descienden hasta $2,7^{\circ} \mathrm{C}$ en las zonas altas. Por el contrario, en los ámbitos de mayor templanza se alcanzan las medias más altas de las máximas $\left(20^{\circ} \mathrm{C}\right)$ y de las mínimas $\left(8,5^{\circ} \mathrm{C}\right)$. Son comunes las heladas por advección o inversión durante el semestre más frío, mientras que en verano las zonas más altas soportan temperaturas calurosas que, en cualquier caso, son mucho menos intensas y duraderas que las que padecen las llanuras y valles periféricos de menor altitud.

La pluviometría media anual varía en función de la posición respecto a los vientos húmedos de W-SW. En las sierras occidentales, mejor expuestas a estos flujos, se llegan a registrar $875 \mathrm{~mm} / \mathrm{año}$. Como contrapunto, en los sectores basales más orientales, a sotavento, se miden entre 400 y $300 \mathrm{~mm} /$ año, sin que su mejor orientación respecto a los vientos del E suponga un incremento pluviométrico considerable debido a la escasa importancia de esta componente como genética de situaciones húmedas. El régimen de las precipitaciones muestra un máximo otoño-invernal, que tiende a desplazarse a la primavera hacia el noreste, y un verano muy seco típicamente mediterráneo.

- Clima mediterráneo periglaciar seco-subhúmedo de altas cumbres béticas

Se limita a la alta montaña de la cordillera Bética por encima de $2.000 \mathrm{~m}$ de altitud, por lo que se limita a $567 \mathrm{~km}^{2}$, concentrados esencialmente en Sierra Nevada. Muy puntual resulta su desarrollo en las cumbres de los macizos de la Sagra, Baza-Filabres, Gádor, Mágina y Tejeda-Almijara. Es un clima frío o muy frío, seco a moderadamente subhúmedo, de marcada aridez estival y con un notable a elevado grado de continentalidad fruto de su desarrollo altitudinal -con índices máximos de hasta 20 (15)-.

Su régimen térmico es el más frío de toda Andalucía como consecuencia de la altitud, 
con valores medios anuales que oscilan entre $10,5^{\circ} \mathrm{C}$ y $2,8^{\circ} \mathrm{C}$, y unos promedios de las máximas y mínimas comprendidos, respectivamente, entre $16^{\circ} \mathrm{C}$ y $7,2^{\circ} \mathrm{C}$, y $6^{\circ} \mathrm{C}$ y $-1,6^{\circ} \mathrm{C}$ Cabe destacar los registros mínimos absolutos invernales de hasta $-20^{\circ} \mathrm{C}$ a $-25^{\circ} \mathrm{C}$ de las cimas más elevadas, la frecuencia de jornadas enteras con temperaturas negativas y las heladas, presentes de 6 a 10-12 meses dependiendo de la altitud. Los extremos máximos estivales rara vez superan los $20-25^{\circ} \mathrm{C}$.

La pluviosidad oscila entre 400 y 750 $\mathrm{mm}$ /año en función de la situación a sotavento o a barlovento de los flujos de componente W. La falta de registros en zonas altas impide establecer con exactitud los promedios pluviométricos de las zonas más elevadas (que seguramente excedan los $1.000 \mathrm{~mm} / \mathrm{año}$ ). El régimen de las precipitaciones presenta un máximo que se prolonga desde mediados del otoño hasta el final del invierno, por lo que una parte muy importante de las precipitaciones son en forma de nieve (la práctica totalidad de las mismas por encima de 2.500 msnm); el verano es muy seco, lo que unido a la fuerte insolación y a los intensos vientos hacen del estío una estación muy árida y extremada, a pesar de su bonanza térmica.

\section{Región de climas del sudeste}

- Clima mediterráneo continental secosemiárido de los altiplanos y piedemontes orientales

Se distribuye a lo largo de $6.237 \mathrm{~km}^{2}$ en las altiplanicies de Guadix, Baza, Huéscar y piedemontes y vertientes basales de los macizos montañosos circundantes, en un rango altitudinal de 700 a $1.400 \mathrm{msnm}$. Se trata de un clima extremado de carácter seco a semiárido, donde prevalecen las estaciones solsticiales sobre las equinocciales, debido a la importante altitud y a la posición intermontañosa de las tierras donde se desarrolla, circunstancias que a su vez lo cualifican como un tipo de elevada continentalidad -la mayor de la región de climas del sudeste-, con unos índices máximos de $19,2(15,5)$.

Las temperaturas medias anuales oscilan entre $11^{\circ} \mathrm{C}$ y $15^{\circ} \mathrm{C}$, quedando los promedios de las máximas y de las mínimas comprendi- dos entre $17^{\circ} \mathrm{C}$ y $22^{\circ} \mathrm{C}$ y $5^{\circ} \mathrm{C}$ y $9,5^{\circ} \mathrm{C}$, con una gradación térmica acorde a las diferencias altitudinales. En todos los casos, estos valores medios son los más bajos de la región. Cabe destacar que este clima presenta las diferencias térmicas absolutas anuales y diarias más elevadas de toda Andalucía -cercanas, respectivamente, a $50^{\circ} \mathrm{C}$ y $30^{\circ} \mathrm{C}$ - como consecuencia del contraste entre los registros extremos del invierno y verano y de la noche y el día, relacionados con fuertes heladas por inversión térmica nocturna y sobrecalentamiento diurno.

La pluviosidad escasa y la importante insolación son determinantes de la sequedad del clima. Los promedios de precipitación anual están en general por debajo de 500 mm, con mínimos locales semiáridos de 280 $\mathrm{mm}$ en enclaves deprimidos y muy aislados de la zonalidad, y máximos aún más puntuales de hasta $680 \mathrm{~mm}$ en determinadas vertientes montañosas, donde son frecuentes fenómenos de retención orográfica de las masas de aire húmedas. El máximo pluviométrico se reparte entre el otoño y la primavera, con un mínimo relativo invernal y otro absoluto estival que reflejan, respectivamente, el carácter continental y la mediterraneidad de este clima.

- Clima mediterráneo semiárido-seco de sierras y piedemontes surorientales

Se localiza en la media ladera, piedemontes y valles intermedios de las sierras más orientales de Andalucía (Filabres, Gádor, Alhamilla, Cabrera y Almagro), en altitudes de entre 400 y 1.200 msnm, con una extensión total de $2.982 \mathrm{~km}^{2}$. Es un clima templado debido a su posición de abrigo orográfico y aerológico. Ello define unos índices moderados de continentalidad, con valores máximos de hasta $17,5(13,8)$.

Los registros medios anuales de temperatura quedan comprendidos entre $13^{\circ} \mathrm{C}$ y $17,5^{\circ} \mathrm{C}$ según la altitud. Los promedios de las máximas se elevan hasta $23,5^{\circ} \mathrm{C}\left(17,5^{\circ} \mathrm{C}\right)$, quedando las mínimas siempre por encima de $8^{\circ} \mathrm{C}\left(12^{\circ} \mathrm{C}\right)$. Los registros estivales son moderadamente altos, como consecuencia de la escasa influencia atemperadora del cercano Mediterráneo, especialmente en episodios de vientos intensos del W cuando, debido 
al efecto Foehn, las máximas franquean los $40^{\circ} \mathrm{C}$, mientras que los inviernos son poco rigurosos en cotas bajas -con débiles heladas- y algo más extremados hacia las zonas más altas.

Este tipo climático presenta una baja pluviometría por la posición marginal de sus tierras respecto a la Circulación del Oeste, quedando la mayor parte de su ámbito por debajo de $400 \mathrm{~mm} / a$ ño, con mínimos localizados de $230 \mathrm{~mm} / \mathrm{año}$ en los valles más interiores, y máximos, igualmente puntuales, cercanos a $600 \mathrm{~mm} / a$ ño, en determinadas elevaciones. El régimen de las precipitaciones presenta un máximo absoluto otoñal, de tipo torrencial, un mínimo secundario invernal, consecuencia de la relativa continentalidad de la comarca y una acusada e inequívoca sequedad estival mediterránea.

- Clima mediterráneo semiárido-árido del litoral del extremo sudeste

Se desarrolla a lo largo de $2.614 \mathrm{~km}^{2}$ en los extremos sur y este de la provincia de Almería, ocupando una serie de tierras costeras, piedemontes y sierras inmediatas litorales y prelitorales hasta altitudes de 400-600 msnm. Constituye el clima más seco -semiárido a árido- no solo de Andalucía y de la Península Ibérica sino también del conjunto de la Europa continental en relación a factores geográficos y dinámicos ya conocidos. Es un tipo de carácter templado, de modesta continentalidad hacia el interior -índices máximos de hasta 16,6-, de moderada oceanidad en la franja costera, cuya capacidad de penetración tierra adentro es escasa debido a la poca recurrencia de los flujos del E.

Las temperaturas medias anuales oscilan entre $15,5^{\circ} \mathrm{C}$ y $19^{\circ} \mathrm{C}$, siendo el extremo superior el más elevado del conjunto de Andalucía. Los promedios anuales de las máximas son notablemente altos -de entre $20,5^{\circ} \mathrm{C}$ y $24,8^{\circ} \mathrm{C}-$, como resultado de la escasa influencia marítima y de los frecuentes vientos de tierra - del W-, causantes de valores absolutos estivales de hasta $40^{\circ} \mathrm{C}$. Los registros medios de las mínimas son moderadamente suaves, no bajando de $10,6^{\circ} \mathrm{C}$ en el interior -con puntuales heladas invernales- y de hasta $14^{\circ} \mathrm{C}$ en los emplazamientos costeros más cálidos. Todos los promedios térmicos son los mayores de la región de climas del sudeste.

Los registros pluviométricos en general quedan por debajo de $350 \mathrm{~mm} /$ año, alcanzado el umbral de la aridez -menos de $200 \mathrm{~mm} /$ año- en determinados puntos, con un mínimo de $152 \mathrm{~mm} / \mathrm{año}$ en cabo de Gata (mínimo europeo continental). Solo el efecto orográfico permite que en enclaves muy locales de las sierras litorales se registren valores cercanos a $450 \mathrm{~mm} /$ año. El régimen torrencial de las lluvias, con un máximo otoñal muy marcado, y la extremada sequedad de los meses estivales encajan en el modelo pluviométrico propio del macroclima Mediterráneo.

\section{Consideraciones finales}

Las clasificaciones zonales -macroclimáticas- carecen de sentido si se quiere mostrar la riqueza climática de ámbitos regionales con marcada heterogeneidad orográfica, tal y como se ha comprobado para el caso de Andalucía (España). De ahí la utilidad de la clasificación climática interescalar y semiautomática inédita propuesta para el caso de la región analizada. Además, cabe destacar que el método utilizado permite su extrapolación a otros ámbitos geográficos a distintas escalas espaciales y temporales.

Como línea a seguir en el área objeto de estudio, se plantea la aplicación del análisis multivariante para periodos de referencia distintos. Ello debería permitir establecer la evolución espacial reciente y las tendencias esperadas del clima en Andalucía y, en su caso, los cambios en los límites de las regiones y en los tipos climáticos identificados en esta investigación. En este sentido, de cara al futuro, muestran especial interés las implicaciones que puedan tener cambios climáticos. $\mathrm{Al}$ respecto, el desarrollo de indicadores para hacer un seguimiento del cambio climático $y$, consecuentemente, diseñar estrategias de adaptación al mismo, serían de especial utilidad para una amplia gama de aplicaciones, en distintos ámbitos (natural y antrópico). Esta cuestión es especialmente relevante en esta zona de la cuenca mediterránea, ya que se prevé que sea una de las regiones más afectadas por el proceso planetario de cambios ambientales. 


\section{Referencias bibliográficas}

ALLUÉ, J.L. Subregiones fitoclimáticas de España. Madrid: I.F.I.E.-Ministerio de Agricultura, 1966.

ALLUÉ, J.L. Atlas fitoclimático de España. Taxonomías. Madrid: I.N.I.A.-Ministerio de Agricultura, Pesca y Alimentación, 2000.

BLAIR, T.A. Climatology: General and regional. New York: Pretence Hall, 1942.

BOSQUE, M. El clima de Granada. Estudios Geográficos, 1957, № 69, p. 447-482.

CAPEL, J.J. Tipos de tiempo de Invierno en la Andalucía Atlántica. Boletín de la Real Sociedad Geográfica, 1975, № 111, p. 7-63.

CAPEL, J.J. El clima de la provincia de Almería. Almería: Publicaciones del Monte de Piedad y Caja de Ahorros de Almería, 1977a.

CAPEL, J.J. El clima de la Cuenca Baja del Guadalquivir. Cuadernos Geográficos, 1977b, $\mathrm{N}^{\circ} 7$, p. 307-350.

CAPEL, J.J. Tipos de tiempo de verano en el Bajo Guadalquivir. Estudios Geográficos, $1978, N^{\circ} 151$, p. 163-185.

CAPEL, J.J. El clima de Andalucía. En: CANO, G. (editor). Geografía de Andalucía. Sevilla: Editorial Tartessos, 1987, p. 99-186.

CAPEL, J.J. El clima de la Península Ibérica. Barcelona: Editorial Ariel, 2000.

CAPEL, J.J. y ANDUJAR, F. Mapa pluviométrico de Andalucía. Revista Paralelo 37, 1978, No 2, p. 197-209.

CAPEL, J.J. y CASTILLO, J.M. El clima de los Estados Unidos Mexicanos. Madrid: C.S.I.C. - Instituto de Geografía Aplicada, 1984.

CASTILLO, J.M. Mecanismos de la precipitación en Sierra Nevada. Cuadernos Geográficos, 1981, № 11, p. 127-152.

CASTILLO, J.M. Precipitaciones y tipos de tiempo en las Béticas-Alto Guadalquivir (An- dalucía Oriental). Madrid: Instituto Nacional de Meteorología, 1985.

CASTILLO, J.M. El clima de Andalucía: clasificación y análisis regional de los tipos de tiempo. Almería: Instituto de Estudios Almerienses, 1989.

CHUVIECO, E. \& CONGALTON, R.G. Using cluster analysis to improve a selection of training statistics in classifying remotely sensed data. Photogrammetric Engineering and Remote Sensing, 1988, Vol. 54, № 9, p. 1275-1281.

DUE, A. El régimen de viento en Granada. Revista de Geofísica, 1959, XVIII, p. 51-55.

FERNÁNDEZ, F. Manual de climatología aplicada. Clima, medio ambiente y planificación. Madrid: Editorial Síntesis, 1995.

FONT, I. Climatología de España y Portugal. Salamanca: Ediciones Universidad de Salamanca, 2000.

FRONTANA, J. El clima de la Costa del Sol de Granada. Aplicaciones socio-económicas. Granada: Universidad de Granada, 1984.

GÓMEZ-ZOTANO, J. Naturaleza y paisaje en la Costa del Sol occidental. Málaga: Centro de Ediciones de la Diputación de Málaga, 2006.

GÓMEZ-ZOTANO, J. y RIESCO-CHUECA, P. Marco conceptual y metodológico para los paisajes españoles: Aplicación a tres escalas espaciales. Sevilla: Consejería de Obras Públicas y Vivienda, Centro de Estudios Paisaje y Territorio, 2010.

IBARRA, P. Una propuesta metodológica para el estudio del paisaje integrado. Geographicalia, 1993, № 30, p. 229-242.

JIMÉNEZ, Y. Los paisajes de Sierra Nevada: cartografía de los sistemas naturales de una montaña mediterránea. Granada: Universidad de Granada, 1991.

KHLEBNIKOVA, E. Environmental Structure and Function: Climate System - Vol. I. Methods of climate classification. In: Encyclopedia of Life Support Systems (EOLSS). De- 
veloped under the Auspices of the UNESCO. Paris: Eolss Publishers, 2009. Disponible en Internet: http://www.eolss.net/sample-chapters/c01/E4-03-05-01.pdf.

MESTRE, A.; NUNES, L.F.; SÁNCHEZ, G.; DIREITINHO, G. y GARCÍA, M.A. (coordinadores). Atlas Climático Ibérico. Madrid: A.E.MET-Ministerio de Medio Ambiente y Medio Rural y Marino del Gobierno de España e Instituto de Meteorología de Portugal, 2011.

OLCINA, J. Métodos de clasificación sinóptica en España. Revisión y propuesta. Estudios Geográficos, 1994, № 215, p. 357 387.

OLIVA, M. \& GÓMEZ-ORTIZ, A. Late-Holocene environmental dynamics and climate variability in a Mediterranean high mountain environment (Sierra Nevada, Spain) inferred from lake sediments and historical sources. The Holocene, 2012, № 22-8, p. 915-927.

OLMEDO-COBO, J.A. y VILLACRECES, M.A. Episodio de lluvias torrenciales del 21 de septiembre de 2007. Las inundaciones de Almuñécar. Cuadernos Geográficos, 2008, № 42, p. 123-148.

PITA, M.F. El riesgo potencial de sequía en Andalucía. Revista de Estudios Andaluces, 1987, No 9, p. 11-40.

PITA, M.F.; BLÁZQUEZ, M.J.; EREZA, M.; MORGA, O. y VALLESPÍ, E. La variabilidad pluviométrica en la cuenca baja del Guadalquivir. Revista de Estudios Andaluces, 1985, $N^{\circ} 4$, p. 167-184

PITA, M.F.; CAMARILLO, J.M. y AGUILAR, M. La evolución de la variabilidad pluviométrica en Andalucía y sus relaciones con el índice de la NAO. En: RASO, J.M. y MARTÍNVIDE, J. (editores). La climatología española en los albores del siglo XXI. Barcelona: Publicaciones de la Asociación Española de Climatología, 1999, p. 399-408.
RASILLA, D.F. Aplicación de un método de clasificación sinóptica a la Península Ibérica. Investigaciones Geográficas, 2003, № 30, p. 27-45.

RIVAS-MARTíNEZ, S. Memoria del Mapa de Vegetación Potencial de España. Itinera Geobotanica, 2011, № 18, p. 5-800.

RIVAS-MARTÍNEZ, S. \& LOIDI, J. Bioclimatology of the Iberian Peninsula. Itinera Geobotanica, 1999, № 13, p. 41-47.

RODRIGO, F.S. \& ESTEBAN-PARRA, M.J. An attempt to reconstruct the rainfall regime of Andalusia (southern Spain) from 1601 A.D. to 1650 using historical documents. Climatic Change, 1994, No 27, p. 397-418.

RODRIGO, F.S.; GÓMEZ, J.J. \& MONTÁVEZ, J.P. Climate variability in Andalusia (southern Spain) during the period 1701-1850 based on documentary sources: evaluation and comparision with model simulations. Climate of the past, 2012, № 8-1, p. 117-133.

SALAS, F.J. y CHUVIECO, E. Aplicación de imágenes Landsat-TM a la cartografía de los modelos combustibles. Revista de Teledetección, 1995, № 5, p. 18-28.

SPAROVEK, G.; DE JONG, Q. \& DOURADO, D. Computer assisted Koeppen climate classification: a case study for Brazil. International Journal of Climatology, 2007, № 27, p. 257-266.

STRAHLER, N. y STRAHLER, A. Geografía física. Barcelona: Editorial Omega, 2000.

VALLE, B. El clima de los Pedroches. Caracterización Agroclimática. Axerquía. Revista de estudios cordobeses, 1982, No 5 , p. 270-304.

VIERS, G. Climatología. Barcelona: Editorial Oikos-Tau, 1981. 